\title{
Using a genetic/clinical risk score to stop smoking (GeTSS): randomised controlled trial
}

\author{
John A. A. Nichols ${ }^{1,4^{*}}$, Paul Grob ${ }^{1}$, Wendy Kite ${ }^{2}$, Peter Williams ${ }^{3}$ and Simon de Lusignan ${ }^{1}$
}

\begin{abstract}
Background: As genetic tests become cheaper, the possibility of their widespread availability must be considered. This study involves a risk score for lung cancer in smokers that is roughly $50 \%$ genetic (50\% clinical criteria). The risk score has been shown to be effective as a smoking cessation motivator in hospital recruited subjects (not actively seeking cessation services).

Methods: This was an RCT set in a United Kingdom National Health Service (NHS) smoking cessation clinic. Smokers were identified from medical records. Subjects that wanted to participate were randomised to a test group that was administered a gene-based risk test and given a lung cancer risk score, or a control group where no risk score was performed. Each group had 8 weeks of weekly smoking cessation sessions involving group therapy and advice on smoking cessation pharmacotherapy and follow-up at 6 months. The primary endpoint was smoking cessation at 6 months. Secondary outcomes included ranking of the risk score and other motivators.

Results: 67 subjects attended the smoking cessation clinic. The 6 months quit rates were $29.4 \%,(10 / 34 ; 95 \% \mathrm{Cl}$ $14.1-44.7 \%)$ for the test group and $42.9 \%(12 / 28 ; 95 \% \mathrm{Cl} 24.6-61.2 \%)$ for the controls. The difference is not significant. However, the quit rate for test group subjects with a "very high" risk score was 89\% (8/9; 95\% Cl 68.4-100\%) which was significant when compared with the control group $(p=0.023)$ and test group subjects with moderate risk scores had a $9.5 \%$ quit rate $(2 / 21 ; 95 \% \mathrm{Cl} 2.7-28.9 \%)$ which was significantly lower than for above moderate risk score $61.5 \%$ $(8 / 13 ; 95 \% \mathrm{Cl} 35.5-82.3 ; p=0.03)$.
\end{abstract}

Conclusions: Only the sub-group with the highest risk score showed an increased quit rate. Controls and test group subjects with a moderate risk score were relatively unlikely to have achieved and maintained non-smoker status at 6 months.

ClinicalTrials.gov ID NCT01176383 (date of registration: 3 August 2010)

Keywords: Smoking cessation, Genetic testing, Lung neoplasms, Primary health care

\section{Background}

Genetic tests in primary care are no longer limited by their exorbitant cost [1] leading the focus to shift from cost to the clinical value of the tests. Researchers have shown that there is a significant genetic familial component to lung cancer risk [2-6] and the recent development of gene-based tests that predict the risk of lung cancer in smokers is an example of a test which may be useful in the primary care setting [7, 8]. A research

\footnotetext{
*Correspondence: drjaan@ntlworld.com

${ }^{4} 60$ Manor Way, Onslow Village, Guildford, Surrey GU2 7RR, UK

Full list of author information is available at the end of the article
}

team in New Zealand has shown a correlation between a genetic test, consisting of 19 single nucleotide polymorphisms (SNPs) and one deletion mutation, and cancer risk (Additional file 1: Appendix S1). When a risk score was calculated from the results of the genetic test and clinical risk factors (COPD, family history of lung cancer and age), this was an accurate predictor for the development of lung cancers $[9,10]$.

They also conducted a controlled trial using this risk score for smoking cessation motivation. They recruited smokers who were recently discharged from hospital but who were not actively planning to quit smoking or enrolling in a smoking cessation programme. Follow-up was 
done by telephone and the lung cancer risk score was calculated and explained to test subjects using a risk graph (Fig. 1). There was a 6 month quit rate of $20 \%$ in subjects with a moderate risk score for lung cancer, $36 \%$ for high risk score and $40 \%$ for very high risk score $[11,12]$. When compared with a $5 \%$ quit rate for the control group and with previous studies using telephone counselling alone [13], the absolute figures for smoking cessation with this risk score was $20-25 \%$ higher [14].

A USA hospital trial of CT screening for lung cancer in smokers and ex-smokers used the same risk score. This trial showed that subjects categorised as having a very high risk score had a 71\% adherence to the CT screening protocol compared with $52 \%$ for the other two categories-high and moderate $(\mathrm{p}<0.05)$. There was no evidence of demotivating effects in the moderate (lowest) risk group $[15,16]$. There have, however, been no UK trials of this gene-based risk score. Our trial was designed to evaluate the risk score as a motivator in an NHS primary care smoking cessation clinic alongside the usual counselling and prescribing protocol [17].

\section{Methods}

We published our protocol and outcome measures a priori [18]. Ethical approval was granted by Surrey Research Ethics Committee.

\section{Recruitment}

Based on previous studies $[8,11,12]$ we estimated that we needed at least 60 subjects to detect statistically significant results [18]. Subjects were recruited from a UK NHS primary care unit using computerised medical records to identify and contact smokers by post (letters signed and sent from their registered GPs). Subjects who replied stating that they wished to stop smoking by attending our clinic were randomised by the principal investigator (PI)

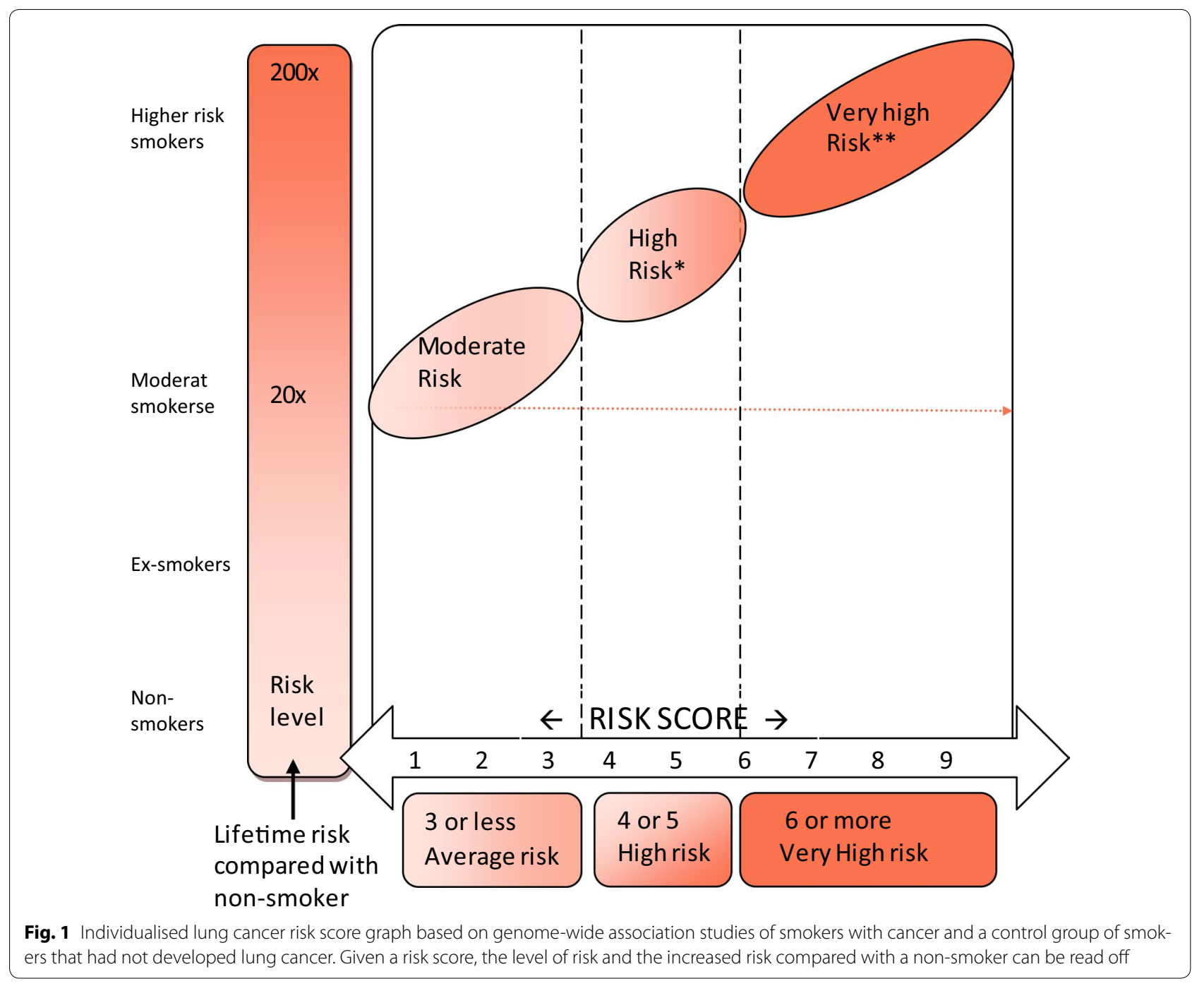


(stratified randomisation to ensure equivalent age and gender mix) to a test group (genetic test and risk score) or control group.

\section{Study design and consent}

Two clinics were run in parallel at the same venue but on different weekdays for test and control groups. Information sheets were posted to all subjects that had expressed an interest in attending the clinic and at first attendance, subjects were seen individually to discuss participation and they were invited to complete a consent form. An initial assessment was carried out using the Fagerström nicotine addiction score [19] and salivary cotinine [20]. Each clinic consisted of 8 smoking cessation sessions and end of trial evaluation at 6 months. A buccal swab was taken for the 20 gene test on the first or second attendance [18]. The 8 weekly smoking cessation sessions included group counselling and advice on smoking cessation pharmacotherapy (varenicline or a range of NRTs).

Lung cancer susceptibility (Fig. 1) was calculated using the Auckland formula [10]:

$$
\begin{aligned}
& \text { Lung cancer score } \\
& \begin{aligned}
= & \text { (number of susceptible genotypes }) \\
& -(\text { number of protective genotypes }) \\
& +3(\text { if lung cancer history in a first degree relative }) \\
& +4(\text { if history of COPD }) \\
& +4(\text { for age }>60 \text { years })
\end{aligned}
\end{aligned}
$$

The gene-based test report included the risk score with an explanation of how the scores relate to the three different risk categories: moderate, high and very high (Fig. 1). The PI saw each patient individually (majority at smoking cessation session 3) to give a full explanation. Some swabs failed to isolate DNA and had to be repeated and some reports were slightly delayed due to administrative issues. Figure 1 also gives an estimate of how many times more likely development of lung cancer is compared with a non-smoker and from this figure the lifetime risk of cancer with continued smoking was estimated in case participants asked for this estimate.

\section{Study setting}

The study took place in the primary care premises of a group general practitioner practice in an English suburb southwest of London. NHS primary care smoking data is very reliably recorded [20]. At the time of this study (2011-13) smoking cessation clinics were commissioned by a Surrey wide NHS body and followed national recommendations [17] which in turn followed an international consensus [17-23]. They were run by two trained NHS Surrey's smoking cessation practitioners who were responsible for the weekly monitoring and group counselling [17].

\section{Primary outcome measures}

The primary endpoint was smoking cessation at 6 months. Although self-reported smoking cessation is usually reliable [24], we also carried out the carbon monoxide breath test and estimation of salivary cotinine [20] at 6 months. There was no monitoring of smoking cessation in the period between the 8 week smoking cessation session and the 6 month follow-up session.

\section{Secondary outcome measures}

Questionnaires were used to evaluate outcomes and secondary endpoints at the 8 week session and at the 6 month follow up clinic session. Although both controls and test group subjects were asked to complete the questionnaires, a question about the motivational value of a gene-based test would not have been relevant to the controls and was omitted from their version of the questionnaire. Participants who failed to attend at 8 weeks and 6 months were contacted by telephone to remind them to complete and forward their questionnaires. When participants found this too difficult, they were completed over the telephone with the PI. The questionnaires were designed to determine which subjects had quit smoking or cut down. They were also asked to score the motivators ( 10 for test group and 9 for controls) for their Influence in helping them to quit (Additional file 2: Appendix S2). The questions in this section were derived from, but not identical to, a previously validated questionnaire [25]. Scoring was:

$$
\begin{aligned}
& 5=\text { Absolute maximum } \\
& 4=\text { Considerable } \\
& 3=\text { Moderate } \\
& 2=\text { A little } \\
& 1=\text { Very little } \\
& 0=\text { None } \\
& -1=\text { Made me smoke more! }
\end{aligned}
$$

Scoring was calculated for individual participants as a percentage of the combined total score for all motivators for that individual. Thus, if the sum of all ten motivators is $2+2+0+4+4+4+3+4+1+2=26$, then the score for a single motivator of 4 is $4 / 26=19.23 \%$. Mean scores were calculated; selected pairs of motivators were compared using the Wilcoxon matched pairs test.

We also asked whether the participant would be likely to recommend a test for lung cancer risk to a friend or family member; an approach, although not without criticism, that is now used for evaluation of hospital and primary care across England [26]. Although this question 
was obviously related to the gene test in the test group the question was put to the controls in terms of an unspecified hypothetical test for risk of lung cancer. An open ended question asked participants to add comments about the concept of a lung cancer risk score.

\section{Results}

\section{Patient characteristics}

109 patients were randomised to test group or control group but 42 failed to attend and enrol. This was before test group recruits were offered the gene test which was not done until the first smoking cessation session. Further analysis of the 42 subjects who failed to attend and register for the trial was not possible as permission to access their records would have required attendance and completion of consent forms. 67 subjects attended and enrolled, 36 in the test group and 31 in the control group (Fig. 2). The mean age and age range were similar in both test and control groups: 49.7 (range: 23-69) years and 49.0 (range: $21-67$ ) years in the test group and control group, respectively. Women comprised $55.6 \%$ of the test group and $54.8 \%$ of the control group. The groups did not differ significantly with respect to the years in education which was calculated based on age at which main education ceased and included tertiary education (41.7\% of test group and $41.9 \%$ of controls). (unpaired $t$ test: $\mathrm{p}=0.517$ ).

\section{Outcomes}

\section{Primary end point}

For the 67 subjects enrolled in the trial $61 \%$ had quit at 8 weeks for both groups but quit rate at 6 months was: $10 / 34(29.4 \%, 95 \%$ CI $14.1-44.7 \%)$ in the test group and $12 / 28(42.9 \%, 95 \%$ CI $24.6-61.2 \%)$ in the control group (Table 2a). Five were completely lost to followup (two from the test group, three from the control group) having moved to another area. At 6 months $41.8 \%(28 / 67)$ failed to attend the follow-up clinic so that confirmation of smoking cessation by a negative salivary cotinine or carbon monoxide breath testing was not possible; 39 subjects did attend and their saliva and breath tests were $100 \%$ concordant with their self-reported smoking status. There were differences in nicotine addiction (see Fagerström score) and rate of completion of varenicline courses between the test group and control group (Tables 1, 2c). When the data were adjusted for these confounding factors using multiple logistic regression (Additional file 3: Appendix S3), the difference in quit rate between the control group and test group subjects with moderate/ high risk scores was not significant $(\mathrm{p}=0.076)$. Comparing the nine very high risk subjects with the 48 controls group subjects at 6 months, a higher proportion of the very high risk group had stopped smoking (8/9, $88.9 \%$, 95\% CI $68.4-100 \%$ versus $12 / 28,42.9 \%, 95 \%$ CI 31.1-54.8\%; Table 3, Fisher's exact test: $\mathrm{p}=0.023$ ). Test group subjects with moderate risk scores had a $2 / 21$ quit rate $(9.5 \%$; $95 \%$ CI $2.7-28.9 \%$ ) which was significantly lower than for above moderate risk score of $8 / 13$ quit rate $\left(61.5 \%\right.$; $95 \%$ CI $35.5-82.3$; Table 3 , $\chi^{2}$ test: $\mathrm{p}=0.03)$.

\section{Secondary end points}

The two feedback questionnaires carried out at 8 weeks and 6 months demonstrated scores for the motivating factors for subjects attempting to stop smoking (Fig. 3). Comparing the rating for the influence at 6 months of the risk score for lung cancer against each of the other motivators for the test group (the control group were not offered the genetic test and therefore not asked about its motivational value), the risk score had a significantly greater influence than smoking restrictions, current health problems, doctor's advice, fact sheet on tobacco risk and saliva cotinine test (Wilcoxon matched pairs test: $\mathrm{p}=0.002,0.022,0.007,0.019$ and 0.047 respectively); the risk score was rated as a motivator equivalent to pressure from the family, cost of smoking and carbon monoxide breath test. When comparing the other motivators against each other utilising both groups of patients, general support for smoking cessation clinic sessions was significantly more influential at 6 months than every other motivator except cost of smoking (Wilcoxon matched pairs tests: all $\mathrm{p}<0.006$; more influential than cost of smoking at $10 \%$ level: $p=0.066$ ). There was a statistically significant higher level of confidence about recommending "a test for lung cancer" risk to family and friends amongst subjects in the test group compared with subjects in the control group at 8 weeks (Mann-Whitney $U$ test, for friends: $\mathrm{p}=0.003$; for family: $\mathrm{p}=0.012$ ). This trend was less marked but still statistically significant at the 6-month follow-up (Mann-Whitney $U$ test for friends: $p=0.033$; for family: $p=0.114$ ). There was a generally positive response to the open ended questions asking how they felt about having had the genetic test and lung cancer risk score (test group) or how they would feel about having a test that would estimate their risk of lung cancer (control group). At the 6 month follow-up $68 \%$ (95\% CI $50.7-85.3 \%$ ) of controls and $72 \%$ (95\% CI $56.9-87.1 \%$ ) of test group stated that a test for lung cancer risk would help them to cut down or quit smoking.

The open ended question also elicited a broad spectrum of opinion with several participants commenting that passive smoking and affects on the health of children and grandchildren was a very significant motivator (Table 4). 


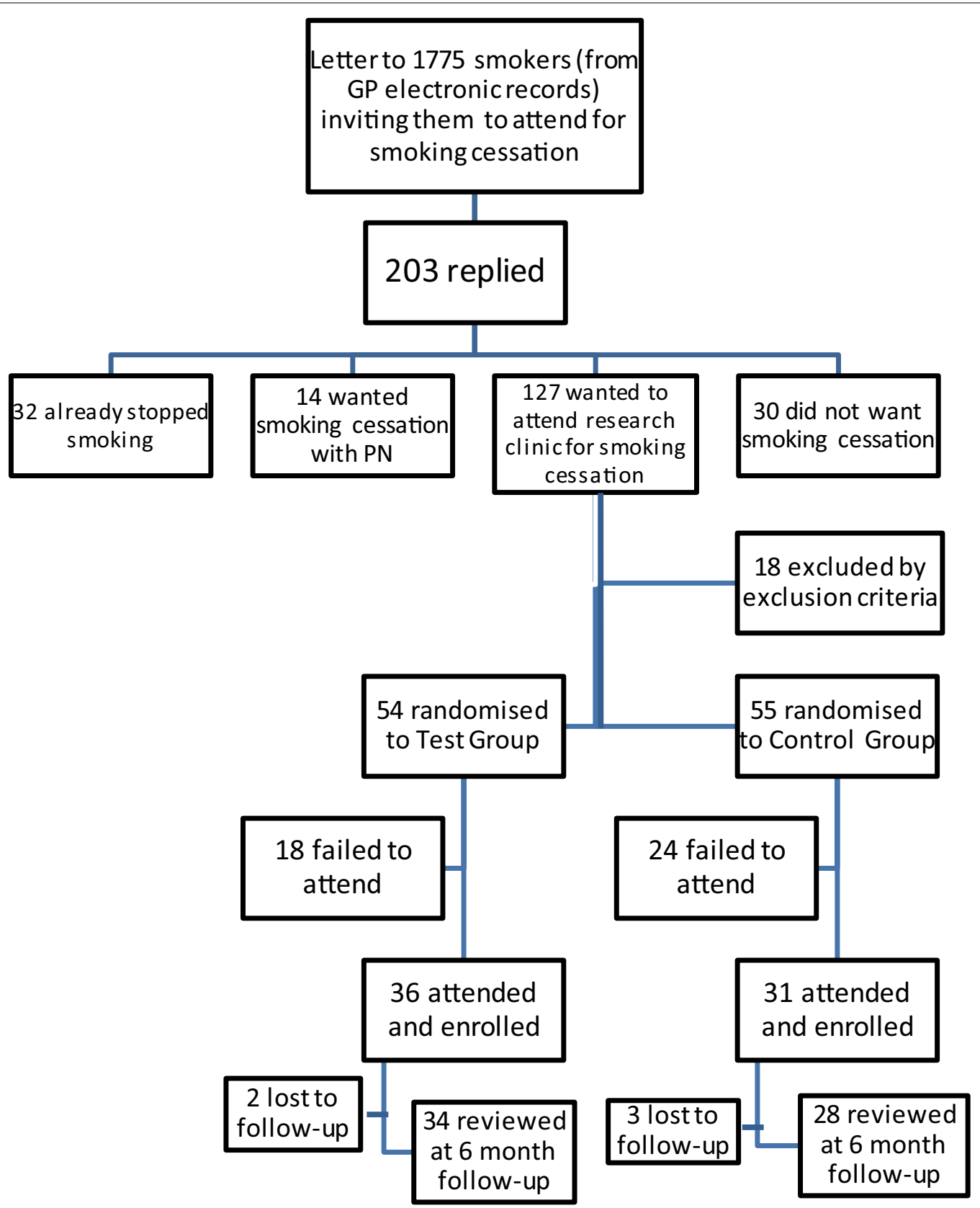

Fig. 2 Recruitment flow chart

\section{Discussion}

\section{Summary of principal findings}

This first trial of a risk score for lung cancer with genetic and clinical components in a primary care setting showed that a very high risk score encourages smoking cessation with a quit rate $46 \%$ higher than controls $(\mathrm{p}=0.023)$ but quit rates for moderate risk scores were $33.4 \%$ lower than controls. Although quit rates were identical at the end of the 8 weeks of smoking cessation sessions there was a higher lapse rate in the test group than controls. The study also demonstrated the feasibility of building genetic tests of this sort into an established smoking cessation service.

\section{Comparison with the literature}

Our results contrast with the findings of Hopkins et al. $[11,12]$. Their test group underwent gene-based testing and their control group did not whilst both groups were 
Table 1 Baseline summary of statistics for treatment groups

\begin{tabular}{llll}
\hline Demographic/smoking feature & Test group $(\mathbf{n}=\mathbf{3 5})$ & Control group $(\mathbf{n}=\mathbf{3 1})$ & p values (test) \\
\hline Gender: female & $20(55.6 \%)$ & $16(53.3 \%)$ & 0.747 (chi square) \\
Mean age (at start of study) & 49.7 & 49.0 & 0.812 (unpaired t) \\
Mean age at completion of education & 18.4 & 18.5 & 0.971 (unpaired t) \\
Years in education (excluding interruptions) & 22.8 & 26.2 & 0.517 (unpaired t) \\
Mean pack years & 32.0 & 28.9 & 0.396 (unpaired t) \\
Mean cigarettes/day at start & 18.1 & 18.1 & 0.993 (unpaired t) \\
Mean Fagerström score & 5.3 & 4.5 & 0.165 (unpaired t) \\
Mean salivary cotinine score at start & 2.5 & 2.3 & 0.389 (unpaired t) \\
Completed course of varenicline & $16(19.4 \%)$ & $19(29 \%)$ & 0.169 (chi square) \\
\hline
\end{tabular}

Table 2 Comparisons between start, 8 weeks and 6 month follow-up for attempted smoking cessation, cigarette consumption and smoking cessation therapy

\begin{tabular}{|c|c|c|c|c|c|c|}
\hline \multirow[t]{2}{*}{ Smoking cessation attempts } & & \multicolumn{5}{|c|}{ Currently non-smoking } \\
\hline & & At start & \multicolumn{2}{|c|}{8 weeks } & \multicolumn{2}{|c|}{ At 6 months follow-up } \\
\hline \multicolumn{7}{|l|}{$2 a$} \\
\hline Test group $(n=36)$ & \multicolumn{2}{|c|}{0} & \multicolumn{2}{|l|}{22} & \multicolumn{2}{|l|}{10} \\
\hline Control group $(n=31)$ & \multicolumn{2}{|c|}{0} & \multicolumn{2}{|l|}{19} & \multicolumn{2}{|l|}{12} \\
\hline Combined data for test and control groups $(n=67)$ & \multicolumn{2}{|c|}{0} & \multicolumn{2}{|l|}{41} & \multicolumn{2}{|l|}{22} \\
\hline \multirow[t]{2}{*}{ Cigarette consumption } & & \multicolumn{5}{|c|}{ Mean values for cigarettes (or cigars $\times 2$ )/day } \\
\hline & & At start & \multicolumn{2}{|c|}{8 weeks } & \multicolumn{2}{|c|}{ At 6 months follow-up } \\
\hline \multicolumn{7}{|l|}{$2 b$} \\
\hline Test group $(n=36)$ & \multicolumn{2}{|c|}{18.11} & \multicolumn{2}{|l|}{3.71} & \multicolumn{2}{|l|}{8.18} \\
\hline Control group $(n=31)$ & \multicolumn{2}{|c|}{18.10} & \multicolumn{2}{|l|}{2.29} & \multicolumn{2}{|l|}{6.68} \\
\hline Combined data for test and control groups $(n=67)$ & \multicolumn{2}{|c|}{18.10} & \multicolumn{2}{|l|}{3.05} & \multicolumn{2}{|l|}{7.50} \\
\hline \multirow[t]{3}{*}{ Smoking cessation therapy } & \multicolumn{6}{|c|}{ Smoking cessation therapy } \\
\hline & \multicolumn{2}{|l|}{ At start } & \multicolumn{2}{|l|}{8 weeks } & \multicolumn{2}{|c|}{ At 6 months follow-up } \\
\hline & Varenicline & NRT & Varenicline & NRT & Varenicline & NRT \\
\hline \multicolumn{7}{|l|}{$2 \mathrm{c}$} \\
\hline Test group $(n=36)$ & 24 & 12 & 16 & 14 & 0 & NK \\
\hline Control group $(n=31)$ & 24 & 7 & 19 & 9 & 0 & NK \\
\hline Combined data for test and control groups $(n=67)$ & 48 & 19 & 35 & 23 & 0 & NK \\
\hline
\end{tabular}

NK not known (not recorded)

Table 3 Test group lung cancer risk according to result of risk score (based on genetic test and clinical criteria) and smoking cessation at 6 months

\begin{tabular}{|c|c|c|c|c|}
\hline \multirow[t]{2}{*}{ Stopped at 6 month follow-up? } & \multicolumn{3}{|c|}{ Estimated risk of lung cancer } & \multirow[t]{2}{*}{ Total } \\
\hline & Moderate risk & High risk & Very high risk & \\
\hline \multirow[t]{2}{*}{ Stopped smoking count \% who had quit smoking } & 2 & 0 & 8 & 10 \\
\hline & $9.5 \%$ & $0 \%$ & $88.9 \%$ & $29.4 \%$ \\
\hline \multirow[t]{2}{*}{ Still smoking count \% who were still smoking } & 19 & 4 & 1 & 24 \\
\hline & $90.5 \%$ & $100.0 \%$ & $11.1 \%$ & $70.6 \%$ \\
\hline Total count & 21 & 4 & 9 & 34 \\
\hline
\end{tabular}




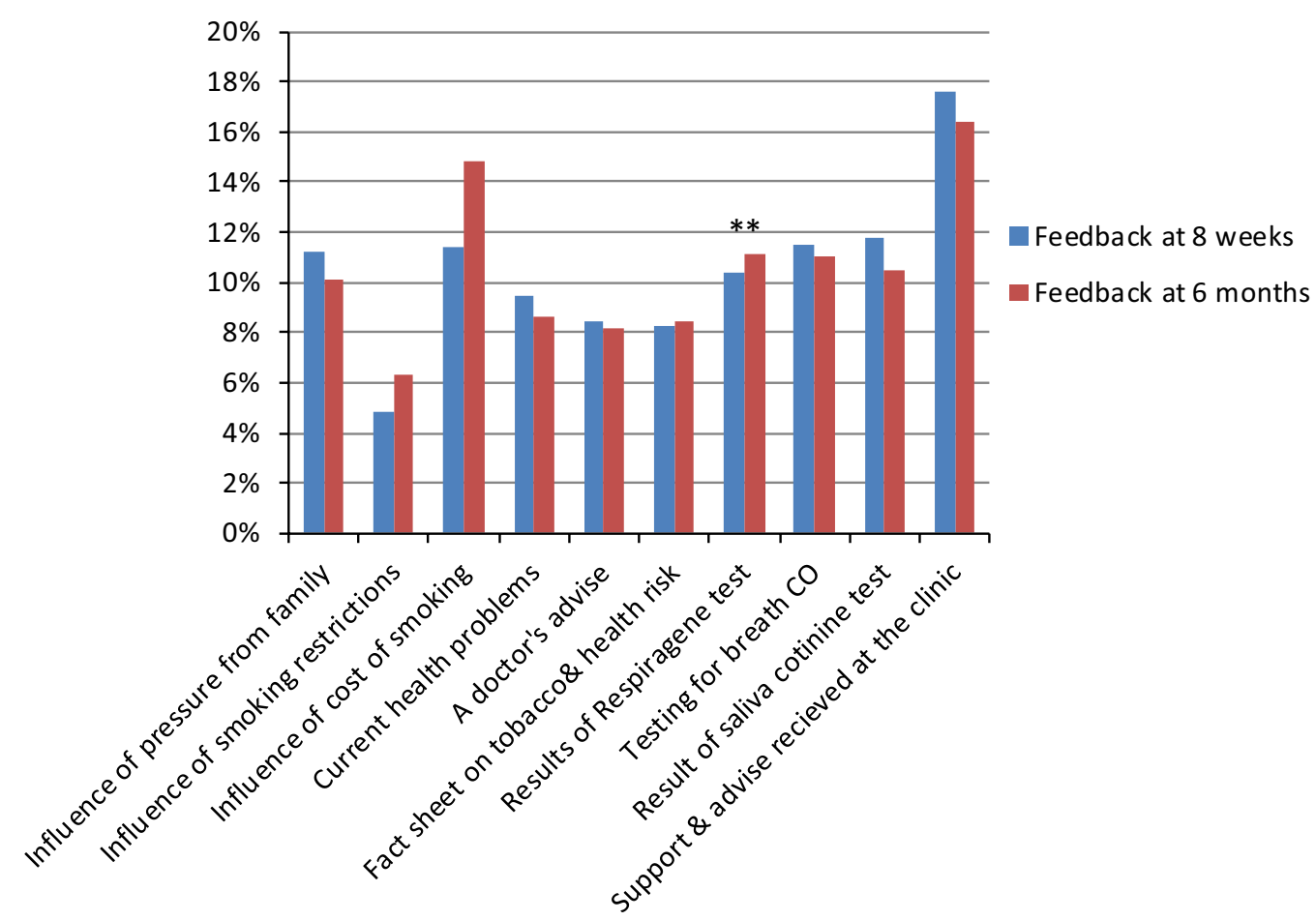

Fig. 3 Mean values for motivators and influences that have helped to reduce or stop smoking: "Please score each of the items below according to how strong an influence they have been in helping you to quit smoking". Scores for motivators for individual participants were calculated as percentages of the sum of total scores of the individual and mean values calculated from these percentage scores (Taken from: [31]). ** Data for "Results of Respiragene test" as a motivator is based on feedback from the test group only

Table 4 Comments from patients including a representative sample of responses to question 7 at the 6 month follow-up session: test group: "How do you feel now about having had a genetic test that estimated the probability that you will develop lung cancer at some future date?", control group: "How would you feel about having a test that estimates the probability that you will develop lung cancer at some future date if you continue smoking?"

\begin{tabular}{|c|c|c|}
\hline \multirow[t]{2}{*}{ Ref no. } & \multicolumn{2}{|l|}{ Group } \\
\hline & $\begin{array}{l}\mathrm{C}=\text { control } \\
\mathrm{T}=\text { test group }\end{array}$ & Comments \\
\hline 1 & $\mathrm{~T}$ & For you to use the test to personalise the message does have a big impact \\
\hline 2 & $\mathrm{~T}$ & $\begin{array}{l}\text { The test made me stop and think. I did need help, likewise other members of group so we could help each other-empa- } \\
\text { thising }\end{array}$ \\
\hline 3 & $\mathrm{~T}$ & My risk score was lower than expected so the "scare factor" not so effective \\
\hline 4 & $\mathrm{~T}$ & The Respiragene test motivated me more at the time than it does now. However, it is still good to know now \\
\hline 5 & $\mathrm{~T}$ & $\begin{array}{l}\text { If I had realised that the course would involve sitting in a circle discussing my smoking habits and so forth, I wouldn't have } \\
\text { come in the first place! }\end{array}$ \\
\hline 6 & $\mathrm{~T}$ & If the group had carried on longer, I wouldn't still me smoking \\
\hline 7 & $\mathrm{~T}$ & The test was worth having but I was mainly concerned about the affect of passive smoking on my grandchildren \\
\hline 8 & C & The stress of separating from my wife has left me smoking again. I would like to have a risk test to help me quit again \\
\hline 9 & C & I wouldn't want a risk test. I believe life goes its own natural course. You've got to die of something \\
\hline 10 & C & I wouldn't mind having a test for lung cancer risk even though it is scary \\
\hline 11 & C & $\begin{array}{l}\text { I am smoking too much. I would end up worrying that the result (of a risk test) will be high but I think it's a reality check I } \\
\text { need }\end{array}$ \\
\hline 12 & C & $\begin{array}{l}\text { The medication (varenicline) made so much difference compared to previous attempts to quit. It took away the mental } \\
\text { pressure }\end{array}$ \\
\hline 13 & C & I am concerned about the affect of passive smoking on my small daughter \\
\hline 14 & C & My orthopaedic surgeon said my fractured arm wasn't healing due to me being a smoker \\
\hline
\end{tabular}


offered brief advice and a smoking cessation information pack with an NRT prescription. The gene-based testing used in both this study and our own study (multiple SNPs plus clinical data) is quite different from the gene-based approach in previous smoking cessation studies $[8,27]$. However, in the Hopkins study, test group subjects had a better quit rate than controls regardless of the score. Possible reasons for these differences are:

1. Their hospital recruited smokers were in the precontemplative-contemplative stage whereas this study involved people from primary care who were in the action stage of quitting. Precontemplative hospital controls, without the benefit of the risk score as a motivator, may be relatively resistant to smoking behaviour change [28].

2. Their test subjects and controls were contacted by telephone after having had only the genetic test whereas our participants attended our clinic regularly for various interventions including group counselling [17]. The high score for "help from the clinic" as a motivator may have masked the motivational effect of the risk score.

Another possible explanation for poor quit rates for subjects with moderate scores is that their relatively low scores encouraged continuation of smoking. Test subjects with moderate risk scores had a $9.5 \%$ quit rate. When this was compared with all other participants this poor quit rate was significant $(p=0.022)$ which suggest that their relatively low risk score may have reassured them that it was safe to carry on smoking or encouraged them to lapse during the 6 month period between the 8 weekly smoking cessation sessions and the 6 month follow-up session.

\section{Strengths and limitations}

This trial of partly genetic risk score as a smoking cessation motivator was the first to investigate a role in primary care. Only $7 \%$ of smokers expressed an interest in our smoking cessation clinic (Fig. 2) which is a fairly typical response rate $[29,30]$. However, this poor recruitment means that the study is underpowered to answer some basic questions such as whether a moderate risk score reassures smokers and encourages them to continue smoking or whether a very high risk score can reliably yield such an impressive quit rate. Further research is urgently needed to clarify the significance of these findings.

Had we administered the Fagerström score questionnaire before randomisation, we could have included this value in randomisation to eliminate the level of nicotine addiction as a confounding factor.

\section{Conclusions}

Since this study is underpowered, a larger multi-centre trial would help to clarify the risk score's motivational value for all risk categories. However, the results suggest that this genetic test and risk estimation is acceptable to most smokers but may be more helpful to higher risk people. The risk score might be especially appropriate as a motivator for patients diagnosed with early COPD.

\section{Additional files}

Additional file 1: Appendix S1. Details of genetic test (marketed as Respiragene).

Additional file 2: Appendix S2. Calculation of motivator scores.

Additional file 3: Appendix S3. Correction of confounding factors.

Additional file 4: Appendix S4. Full data set for trial.

\section{Abbreviations}

COPD: chronic obstructive pulmonary disease; Cl: confidence interval; DNA: deoxyribonucleic acid; GP: general practice; NHS: National Health Service of the United Kingdom; NRT: nicotine replacement therapy; NS: statistically nonsignificant; PI: principal investigator; PN: practice nurse; UK: United Kingdom; SNP: single nucleotide polymorphism.

\section{Authors' contributions}

$\mathrm{JN}$ was involved in developing the research idea carried out the research, the analysis of the results and the final draft of the manuscript. PG also helped to develop the research idea. WC advised on aspects of the protocol associated with smoking cessation. SdeL helped to finalise the protocol and help to draft the manuscript. PW participated in the design of the study and performed the statistical analysis. All authors read and approved the final manuscript.

\section{Author details}

${ }^{1}$ Department of Clinical and Experimental Medicine, University of Surrey, Guildford, Surrey GU2 7XH, UK. ${ }^{2}$ Jardim De Bensafrim, Lote 8, Bensafrim 8600 069, Argave, Portugal. ${ }^{3}$ Department of Mathematics, University of Surrey, Guildford, Surrey GU27XH, UK. ${ }^{4} 60$ Manor Way, Onslow Village, Guildford, Surrey GU2 7RR, UK.

\section{Acknowledgements}

The authors would like to thank A Telaranta-Keerie and the staff of Lab 21, Cambridge for their help with processing and analysing swabs for genetic testing; A Roscoe and the staff of the Integrated Care Partnership, Epsom for help with recruitment and premises and Surrey Smoking Cessation Practitioners $J$ Golding and $\mathrm{H}$ Phillips for their expertise. We are grateful for support from Lab 21 and Synergenz Bioscience Ltd without which this research could not have been completed.

Wendy Kite-Retired.

\section{Competing interests}

The authors declare that they have no competing interests.

\section{Availability of data}

The complete data supporting the conclusions of this article is presented in Additional file 4: Appendix S4.

\section{Consent to publish}

The participants provided written informed consent to publish data from their initial interviews.

Ethical approval, sponsorship and consent to participate Ethical approval was granted by Surrey Research Ethics Committee 23 June 2011 (Ref 10/H1109/53). The study was overseen by our sponsor, Sussex NHS Research Consortium, who carried out a site inspection. Potential participants 
had been mailed a comprehensive fact sheet about the trial and were subsequently seen individually to discuss participation. All participants provided written informed consent to participate in the study by signing.

\section{Funding}

The study was supported by funding from Lab 21, Cambridge, UK and Synergenz Bioscience Ltd, Evanston, USA. Representatives of the funding bodies met the authors to discuss the proposed project but made no subsequent contribution and were not involved in analysis of the data, interpreting the data or in writing the manuscript

\section{Publisher's Note}

Springer Nature remains neutral with regard to jurisdictional claims in published maps and institutional affiliations.

\section{Received: 25 July 2016 Accepted: 13 October 2017}

Published online: 23 October 2017

\section{References}

1. Wetterstrand KA. DNA sequencing costs: data from the NHGRI genome sequencing program (GSP). 2015. https://www.genome.gov/sequencingcosts/. Accessed Jun 2016.

2. Carr S, Akerly W, Hashibe M, Canon-Albright LA. Evidence for a genetic contribution to non-smoking-related lung cancer. Thorax. 2015;70(11):1033-9.

3. Marcy TW, Stefanek M, Thompson KM. Genetic testing for lung cancer risk: if physicians can do it, should they? J Gen Int Med. 2002;17(12):946-51.

4. Gao P, Zhao H, You J, Jing F, Hu Y. Association between interleukin8-251 A/T polymorphism and risk of lung cancer: a meta-analysis. Cancer Investig. 2014;32(10):518-25.

5. Bu ZB, Ye M, Cheng Y, Wu WZ. Molecular epidemiology of human cancer risk: gene-environment interactions and p53 mutation spectrum in human lung cancer. Methods Mol Med. 2003;74:43-59.

6. Li G, Wang LE, Chamberlain RM, Amos Cl, Spitz MR, Wei Q. p73 G4C14-to-A4T14 polymorphism and risk of lung cancer. Cancer Res. 2004;64(19):6863-6.

7. Smerecnik C, Grispen JEJ, Quaak M. Effectiveness of testing for genetic susceptibility to smoking-related diseases on smoking cessation outcomes: a systematic review and meta-analysis. Tob Control. 2012;21(3):347-54.

8. Sanderson SC, Neill SC, White DB, Bepler G, Bastian L, Lipkus IM, McBride CM. Responses to online GSTM1 genetic test results among smokers related to patients with lung cancer: a pilot study. Cancer Epidemiol Prev Biomark. 2009;18(7):1953-61.

9. Young RP, Hopkins RJ, Hay BA, Epton MJ, Mills GD, Black PN, Gardner HD, Sullivan R, Gamble GD. Lung cancer susceptibility model based on age, family history and genetic variants. PLoS ONE. 2009:4(4):e5302.

10. Young RP, Hopkins RJ, Hay BA, Gamble GD. GWAS and candidate SNPs for COPD and lung cancer combine to identify lung cancer susceptibility: validation in a prospective study. Am J Respir Crit Med. 2010;181:A3738.

11. Hopkins RJ, Young RP, Hay B, et al. Lung cancer risk testing enhances NRT uptake and quit rates in randomly recruited smokers offered a gene based risk test. Am J Respir Crit Med. 2012;185:A2590.

12. Hopkins RJ, Young RP, Hay B, et al. Gene-based lung cancer risk score triggers smoking cessation in randomly recruited smokers. Am J Respir Crit Med. 2011:183:A5441.

13. West R, Shiffman S, McLean D. Fast facts: smoking cessation (fast facts series). London: Paperback; 2007.

14. Young RP, Hopkins RJ, Smith M, Hogarth DK. Smoking cessation: the potential role of risk assessment tools as motivational triggers. Postgrad Med J. 1011;2010(86):26-33.

15. Lam VK, Miller M, Dowling L, Singhal S, Young RP, Cabebe E. Community low-dose ct lung cancer screening: a prospective cohort study. Lung. 2015;193:135-9.

16. Young RP, Hopkins RJ, Cabebe E, Miller M, Gamble G. Low-dose computer tomography (ct) lung cancer screening in the community: a prospective cohort study (react) incorporating a gene-based lung cancer risk test. Am J Respir Crit Care Med. 2015;2015(191):A3569.
17. NHS Local stop smoking services, services delivery and monitoring guidance 2011/12. https://www.gov.uk/government/uploads/system/ uploads/attachment_data/file/212940/9193-TSO-2900254-NHS-StopSmoking_Accessible.pdf. Accessed 19 Jun 2016.

18. Nichols JA, Grob P, Kite W, de Lusignan S, Williams P. Genetic test to stop smoking (GeTSS) trial protocol: randomised controlled trial of a genetic test (Respiragene) and Auckland formula to assess lung cancer risk. BMC Pulm Med. 2014;14:77.

19. Pomerleau CS, Carton SM, Lutzke ML, Flesslan KA. Reliability of the fagerstrom tolerance questionnaire and the fagerstrom test for nicotine dependence. Addict Behav. 1994;19(1):33-9.

20. Cope G, Nayyar P, Holder R, Brock G, Chapple I. Near-patient test for nicotine and its metabolites in saliva to assess smoking habit. Ann Clin Biochem. 2000;37(5):666-73.

21. de Lusignan S, Hague N, van Vlymen J, Kumarapeli P. Routinely-collected general practice data are complex, but with systematic processing can be used for quality improvement and research. Inform Prim Care. 2006;14(1):59-66

22. Miller M, Wood L. Effectiveness of smoking cessation interventions: review of evidence and implications for best practice in Australian health care settings. Aust N Z J Public Health. 2003;27(3):300-9.

23. Brose LS, West R, McDermott MS, Fidler JA, Croghan E, McEwen A. What makes for an effective stop-smoking service? Thorax. 2011;66(10):924-6.

24. Davis AL, Faust R, Ordentlich M. The accuracy of self-reported smoking: a systematic review of the relationship between self-reported and cotinine-assessed smoking status. Nicotine Tob Res. 2009;11(1):12-24.

25. West R. Feasibility of a national longitudinal study (The Smoking Toolkit Study) to monitor smoking cessation and attempts at harm reduction in the UK. 2006. http://www.google.co.uk/url?sa $=t \& r c t=j \& q=\& e s r c=s$ \&source $=$ web\&cd =1\&ved =0CCQQFjAA\&url=http\%3A\%2F\%2Fwww. smokinginengland.info\%2Fdownloadfile\%2F\%3Ftype\%3Dreport\%26src \%3D4\&ei=4htnVffVA4XjU4ebgeAM\&usg=AFQjCNH6SchP4XbrwkqBdLM P7bjZBcJi60\&sig2=cuiBYeFUWG8 17pKuWE4OQ\&bvm=bv.93990622,d. d24. Accessed Jun 2016

26. Davis R, Briggs M, Arora S, Sharma E, Asgheddi M. Patient experience. Friends and family fails the clinicians' test. Health Serv J. 2014;124(6408):20-1.

27. Young RP, Hopkins RJ. Incorporating genomic data into multivariate risk models for lung cancer. Genet Med. 2013;15(8):667-8.

28. Prochaska JO, DiClemente CC. Stages and processes of self-change of smoking: toward an integrative model of change. J Consult Clin Psychol. 1983:51(3):390-5.

29. McClure JB, Greene SM, Wiese C, Johnson KE. Interest in an online smoking cessation program and effective recruitment strategies: results from project quit. J Med Internet. 2006;8(3):e14

30. Lichtenstein $\mathrm{E}_{1}$ Hollis J. Patient referral to a smoking cessation program: who follows through? J Fam Pract. 1992;34(6):739-44.

31. Nichols JAA. How effective is fear of lung cancer as a smoking cessation motivator in lung cancer? In: Adonis M, editor. Prevention, diagnosis and treatment of lung cancer. Rijeka: InTech; 2017.

\section{Submit your next manuscript to BioMed Central and we will help you at every step:}

- We accept pre-submission inquiries

- Our selector tool helps you to find the most relevant journal

- We provide round the clock customer support

- Convenient online submission

- Thorough peer review

- Inclusion in PubMed and all major indexing services

- Maximum visibility for your research

Submit your manuscript at www.biomedcentral com/submit
Ciomed Central 